\title{
Inquiring the photocatalytic activity of cuprous oxide nanoparticles synthesized by a green route on methylene blue dye
}

\author{
Manoranjan Behera $^{1} \cdot$ Gitisudha Giri $^{1}$
}

Received: 16 June 2015 / Accepted: 23 February 2016/Published online: 17 March 2016

(C) The Author(s) 2016. This article is published with open access at Springerlink.com

\begin{abstract}
We synthesized cuprous oxide $\left(\mathrm{Cu}_{2} \mathrm{O}\right)$ nanoparticles (NPs) with an average crystallite size of $8.8 \mathrm{~nm}$ in presence of Arka (Calotropis gigantea) leaves extract. The photo-bleaching activity of $\mathrm{Cu}_{2} \mathrm{O}$ NPs on the aqueous methylene blue (MB) dye was studied by illumination of visible light. In the absorption spectra, a decrease in the absorption peak intensity at $665 \mathrm{~nm}$ of $\mathrm{MB}$ was observed in presence of $\mathrm{Cu}_{2} \mathrm{O}$ NPs. A red shift in its peak position as a function of irradiation time is suggesting that oxide particles are degrading the organic dye in an aqueous medium. In the vibration spectra, red shift in the $\mathrm{C}-\mathrm{H}$ stretching band $\left(2954,2926\right.$, and $\left.2855 \mathrm{~cm}^{-1}\right)$ of methylene group and $\mathrm{C}-\mathrm{N}$ stretching band (1343 and $1226 \mathrm{~cm}^{-1}$ ) of $\mathrm{MB}$ in presence of $\mathrm{Cu}_{2} \mathrm{O}$ NPs proposes a surface adsorption of MB over NP's surfaces. Quenching in the emission band intensity and red shifts in the peak maxima of $\mathrm{MB}$ in presence of $\mathrm{Cu}_{2} \mathrm{O}$ NPs is ascribed to the charge transfer interaction between MB and oxide NPs. A linear SternVolmer plot reveals that decrease in the emission intensity of MB dye occurs via the dynamic quenching mechanism. Synthesis of $\mathrm{Cu}_{2} \mathrm{O}$ NPs of various architectures using a green route could be use as an approach towards the costeffective treatment of water pollutants.
\end{abstract}

Keywords Photodegradation - Methylene blue dye . Surface adsorption - Charge transfer interaction . Photoluminescence quenching

Manoranjan Behera

mano.silicon@gmail.com

1 Silicon Institute of Technology, Bhubaneswar, Odisha, India

\section{Introduction}

Organic dyes are the major threats to our environments. It is not an easy task to remove them from dye-bearing waste waters owing to their stability towards oxidizing agents [13]. Amongst the various organic dyes, methylene blue (MB) - a cationic dye mostly used in paper, rubber, and textile industry as colorants-is found in waste water [46]. It is reported that acute exposure to MB dye might cause tissue narcosis, heart stroke, jaundice, etc., in humans $[7,8]$. Presently a variety of physical, chemical, and biological methods were available for the treatment of dye contaminated water. From an extensive literature study, we concluded that a chemical method such as adsorption process is an economical and efficient route for elimination of toxic dyes from polluted water [9-12]. In this regards, various low-cost adsorbents such as fly ash, metal sulfides $\left(\mathrm{Ag}_{2} \mathrm{~S}\right.$ ), and metal oxides (titania $\mathrm{TiO}_{2}$, cuprous oxide $\mathrm{Cu}_{2} \mathrm{O}$ ) have already been tested to treat polluted water [4, 9-13]. In recent years, semiconductor nanoparticles (NPs) were extensively used by scientists and academicians around the globe for the removal of various organic dyes via adsorption route. Pourahmad [4] reported that $\mathrm{Ag}_{2} \mathrm{~S}$ NPs encapsulated in a mesoporous material can efficiently degrade MB dye in aqueous solution. In another work, Srinivasan and White [13] reported an accelerated photodegradation of $\mathrm{MB}$ over three-dimensionally ordered macroporous $\mathrm{TiO}_{2}$ pore sizes lies between 0.5 and $1 \mu \mathrm{m}$. However, owing to high band gap of $3.2 \mathrm{eV}, \mathrm{TiO}_{2}$ cannot perform in the visible region.

Among the various semiconductor metal oxides as photocatalyst, $\mathrm{Cu}_{2} \mathrm{O}$ NPs find a special place in photocatalysis under visible light [10-12, 14-16]. Wide applications of this oxide NPs are mainly owing to its nontoxicity, easy availability of cheap and up-scalable 
synthetic routes, lying of the band gap (i.e., $2.17 \mathrm{eV}$ ) in the visible range, tunability of band gap, and strong tendency to adsorb molecular oxygen which helps in scavenging the photogenerated electrons so that electron-hole pairs recombination can be restrained easily at the interface [10$12,14-16]$. It is reported that size and shape are of paramount importance in tailoring the various properties and applications of the $\mathrm{Cu}_{2} \mathrm{O}$ NPs. A variety of $\mathrm{Cu}_{2} \mathrm{O}$ nanostructures such as wires, boxes, cubes, truncated cubes, octahedra, nanocages, nanomultipods, spheres, and a variety of hollow structures have already been synthesized and tested for their photocatalytic activity on various organic compounds $[14,15]$. To develop diverse architectures of $\mathrm{Cu}_{2} \mathrm{O}$, the various methods widely used includes hydrothermal method, microemulsion method, surfactantassisted route, and wet chemical method [10-12, 14-16]. Sun et al. [9] have reported an enhanced photocatalytic activity for $\mathrm{Cu}_{2} \mathrm{O}$-graphene oxide (GO) nanocomposite synthesized via solvothermal route towards Rhodamine B $(\mathrm{RhB})$ dye. They reported that more than $65 \% \mathrm{RhB}$ was degraded within $80 \mathrm{~min}$ of visible light irradiation. Cai et al. [10] have reported synthesis of $\mathrm{Cu}_{2} \mathrm{O}$-reduced $\mathrm{GO}$ (rGO) composite by a one-pot hydrothermal method using glucose as reducing and cross-linking agent. They reported that as rGO promotes the charge carrier separation, it increases the aqueous photocatalytic efficiency. But, nearly $70 \%$ methyl orange (MO) degradation was reported for this nanocomposite after a long irradiation time of $300 \mathrm{~min}$. In another article, Zhang et al. [11] have reported $80 \% \mathrm{MO}$ degradation after $30 \mathrm{~min}$ irradiation by graphene/defected $\mathrm{Cu}_{2} \mathrm{O}$ nanocomposite synthesized via a chemical vapor deposition method. They stressed on the importance of O-atoms towards the charge carrier separation. Zou et al. have reported synthesis of $\mathrm{Cu}_{2} \mathrm{O}-\mathrm{rGO}$ nanocomposites of various $\mathrm{Cu}_{2} \mathrm{O}$ crystal facets. They have reported only 72,60 and $28 \% \mathrm{MB}$ degradation after $120 \mathrm{~min}$ for octahedral, dodecahedral and cubic faceted $\mathrm{Cu}_{2} \mathrm{O}-\mathrm{rGO}$ NPs.

A few reports are available on photocatalytic activity study of $\mathrm{Cu}_{2} \mathrm{O}$ NPs synthesized by green chemical route. $\mathrm{Cu}_{2} \mathrm{O}$ microcrystals with well-formed facets were synthesized by a simple hydrothermal method by Zheng et al. [14] and investigated the surface stabilities and photocatalytic properties of the synthesized $\mathrm{Cu}_{2} \mathrm{O}$ microcrystals. It is reported that $\mathrm{Cu}_{2} \mathrm{O}\{100\}$ and $\{110\}$ facets gradually disappear and transform into nanosheets during the photodegradation of MO dye. With the increase of irradiation time, $\mathrm{Cu}_{2} \mathrm{O}$ microcrystals completely transform into nanosheets with $\{111\}$ facets and the finally formed nanosheets exhibit stable photocatalytic activities. Zhu et al. [17] have synthesized $\mathrm{Cu}_{2} \mathrm{O}$ micro-/nanocrystals using a simple liquid phase reduction process under microwave irradiation. In particular, for the dandelion morphology, the photocatalytic degradation rates of $\mathrm{RhB}$ dye is reported to be highest, i.e., $56.37 \%$. From above literature studies we concluded that photodegradation efficiency of $\mathrm{Cu}_{2} \mathrm{O}$ towards a dye depends on various parameters such as nature of the dye, synthesis route, shape and size of NPs, attachment of charge carrier separating agent to NP, adsorption capability, surface area, etc.

As we have not found any report on MB degradation by $\mathrm{Cu}_{2} \mathrm{O}$ NPS obtained via a green route, in this manuscript we report on visible light photodegradation of MB dye by biosurfactant-capped $\mathrm{Cu}_{2} \mathrm{O}$ NPs synthesized via a green route using leaves extract of Arka plant (i.e., Calotropis gigantea). The saponin molecules present in the plant extract not only acts as stabilizing agent [18] but is also believed to act as charge carrier separator. The synthesized nano-powders were characterized using UV-visible spectroscopy, Fourier transform infrared (FTIR) spectroscopy, $\mathrm{X}$-ray photoelectron spectroscopy (XPS), X-ray diffraction (XRD), zeta potential, dynamic light scattering (DLS), photoluminescence (PL) spectroscopy, field emission scanning electron microscope (FESEM) and transmission electron microscope (TEM).

\section{Experimental}

\section{Synthesis of $\mathrm{Cu}_{2} \mathrm{O}$ NPs}

We synthesized $\mathrm{Cu}_{2} \mathrm{O}$ NPs by a green synthetic route using copper sulfate $\left(\mathrm{CuSO}_{4} \cdot 5 \mathrm{H}_{2} \mathrm{O}\right)$ crystals as precursor salt, Arka leaves extract as encapsulating agent, and hydrazine hydrate as reducing agent in an aqueous medium. In an aim to synthesize $\mathrm{Cu}_{2} \mathrm{O}$ NPs, first we prepared a precursor salt solution $(1 \mathrm{M})$ by dissolving $\mathrm{CuSO}_{4} \cdot 5 \mathrm{H}_{2} \mathrm{O}$ crystals in double-distilled water. After that, an aqueous plant extract was made by adding about $10 \mathrm{~g}$ of Arka leaves to $100 \mathrm{~mL}$ water in a conical flask and was boiled for $1 \mathrm{~h}$ in a hot plate. Now, the two solutions were mixed in a proper ratio and stirred in a magnetic stirrer for half an hour at $70{ }^{\circ} \mathrm{C}$. Under the stirring condition, reducing agent was added dropwise till the blue color (i.e., due to $\mathrm{Cu}^{2+}$ ions) changed to a permanent reddish-brown suspension consisting of cuprous oxide $\left(\mathrm{Cu}_{2} \mathrm{O}\right)$ NPs. The aqueous suspensions thus obtained was kept standstill overnight to settle down $\mathrm{Cu}_{2} \mathrm{O}$ NPs. After careful decantation of upper supernatant liquid, those solid particles which were settled at the bottom of the container were kept in an electrical oven maintained at $80{ }^{\circ} \mathrm{C}$ for $2 \mathrm{~h}$ for complete removal of solvent so that samples can be collected in powder form. To confirm the formation of $\mathrm{Cu}_{2} \mathrm{O}$ NPs, we added $2 \mathrm{~mL}$ of concentrated ammonia solution to $10 \mathrm{mg} \mathrm{Cu}_{2} \mathrm{O}$ powders taken in a 25-mL beaker. A clear blue solution results from formation of $\left[\mathrm{Cu}\left(\mathrm{NH}_{3}\right)_{4}\left(\mathrm{H}_{2} \mathrm{O}\right)_{2}\right]^{2+}$ complex after shaking the beaker 
for a few seconds which indicates formation of copper(I) oxide [19]. The dried nano-powders were stored in desiccators for characterizations.

\section{Characterization techniques}

We characterized the as-synthesized $\mathrm{Cu}_{2} \mathrm{O}$ powders using UV-visible spectroscopy, FTIR spectroscopy, XPS, XRD, zeta potential, DLS, PL spectroscopy, FESEM and TEM. UV-visible absorption spectra were acquired on a PerkinElmer spectrophotometer. The crystal phase of synthesized NPs was identified using an X-ray diffractometer (Rigaku D/Max 2000). Vibration spectra have been studied for the powder samples with a Thermo Nicolet Corporation FTIR Spectrometer (Model NEXUS-870). X-ray photoelectron spectrum (XPS) was collected on a VG ESCALAB MK-II spectrometer with a monochromatic $\mathrm{Al} \mathrm{K} \alpha$ source $(h v=1486.6 \mathrm{eV})$ operated at $10 \mathrm{kV}$ and $20 \mathrm{~mA}$ at $10^{-9} \mathrm{~Pa}$. Sample for XPS was prepared by drop-casting method. A drop of aqueous dispersion of $\mathrm{Cu}_{2} \mathrm{O}$ NPs was placed on the silicon substrate and allowed to dry in desiccators by keeping overnight at room temperature. Zeta potential was measured using a Malvern Nano ZS instrument using phase analysis light scattering technique. Solid samples were sonicated for $20 \mathrm{~min}$ to well disperse oxide NPs in water prior to measuring zeta potential $(\xi)$. The Malvern Nano ZS instrument was also used to find hydrodynamic diameter $\left(D_{\mathrm{h}}\right)$ of the aqueous suspension before and after adding $\mathrm{Cu}_{2} \mathrm{O}$ NPs to MB dye. The dispersed samples were analyzed at least for thrice at $25{ }^{\circ} \mathrm{C}$ to get accurate results. The PL spectra have been recorded with a computer-controlled Perkin-Elmer (Model-LS 55) luminescence spectrometer in conjugation with a red-sensitive photomultiplier tube detector (RS928) and a highenergy pulsed Xe-discharge lamp as an excitation source (average power $7.3 \mathrm{~W}$ at $50 \mathrm{~Hz}$ ). Image of a biosurfactantmodified $\mathrm{Cu}_{2} \mathrm{O}$ nanocomposite powder was studied using FESEM of ZEISS SUPRA-4O and TEM of JEM-2100 (JEOL, Japan) machines. TEM sample was prepared by placing one drop of diluted solution on a carbon-coated 600-mesh copper grid and allowing the sample to dry in desiccators at room temperature. In the FESEM studies, the sample was spin-coated on a (110) silicon plate and then a thin gold coating was sputtered to make a conducting surface.

\section{Photocatalytic degradation}

To study the photodegradation of $\mathrm{MB}$ dye in an aqueous medium, first we prepared a suspension of $\mathrm{Cu}_{2} \mathrm{O}$ particles $(100 \mathrm{mg}$ ) by dispersing it in a $500 \mathrm{~mL}$ solution of $\mathrm{MB}$ $(20 \mathrm{mg} / \mathrm{L})$ in water. The aqueous suspension was then sonicated for $20 \mathrm{~min}$ in dark to make the powders disperse well in the solution before irradiation with visible light. The photocatalytic reaction was conducted in a $500-\mathrm{mL}$ cylindrical glass reactor. We used $500 \mathrm{~W}$ Xenon lamp with a UV cutoff filter as visible light source. The dispersion was bubbled with $100 \mathrm{~mL} / \mathrm{min} \mathrm{O}_{2}$ and stirred magnetically at $30{ }^{\circ} \mathrm{C}$. At regular intervals, $15 \mathrm{~mL}$ of the suspension was sampled and separated by centrifugation at $4000 \mathrm{rpm}$ for $10 \mathrm{~min}$ to remove the powder. The concentration of residual MB (i.e., supernatant liquid) was measured by its absorbance $(A)$ at $665 \mathrm{~nm}$ with a Perkin-Elmer spectrophotometer. The degradation efficiency $(D)$ of $\mathrm{MB}$ was calculated using the equation, $D=\left(A_{0}-A\right) / A_{0} \times 100 \%$, where $A_{0}$ is the absorbance of $20 \mathrm{mg} / \mathrm{L}$ MB at $665 \mathrm{~nm}, A$ is the absorbance at the same wavelength of the extracted solution. As a control, another sample was analyzed without irradiating to test the adsorption ability of the oxide catalyst; other test methods were the same, as mentioned above.

\section{Results and discussion}

\section{UV-visible spectra}

Figure 1 shows evolution of absorption spectra (400-900 nm) of MB in presence of $\mathrm{Cu}_{2} \mathrm{O}$ NPs upon irradiation of visible light; (a) 0 , (b) 10, (c) 20, (d) 30, (e) 60, (f) 90, and (g) $120 \mathrm{~min}$ at room temperature. Before irradiating, MB solution with $\mathrm{Cu}_{2} \mathrm{O}$ NPs was kept in the dark for nearly $3 \mathrm{~h}$ to eliminate possibility of other effects such as adsorption and reaction without light to affect the result. As shown in Fig. 1, MB displays two absorption bands, one near $605 \mathrm{~nm}$ and other one near $665 \mathrm{~nm}$. The decrease in the intensity of absorption peaks with time elapsed is ascribed to degradation of $\mathrm{MB}$ by $\mathrm{Cu}_{2} \mathrm{O}$ NPs. For

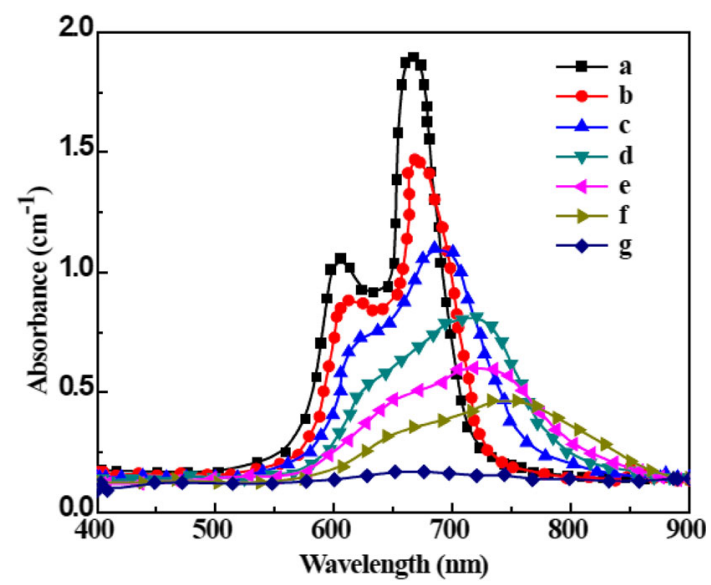

Fig. 1 Absorption spectra of $\mathrm{MB}$ in presence of $\mathrm{Cu}_{2} \mathrm{O}$ NPs upon irradiation of visible light; $a 0, b 10, c 20, d 30, e 60, f 90$, and g $120 \mathrm{~min}$ 
example, at $665 \mathrm{~nm}$, the absorbance has decreased from 1.9 to $1.46 \mathrm{~cm}^{-1}$ after irradiation for only $10 \mathrm{~min}$ and this value has decreased to as small as $0.14 \mathrm{~cm}^{-1}$ after $120 \mathrm{~min}$ irradiation of visible light. This reveals that rate of decomposition of MB increases very fast with time. The extremely low intensity of $665 \mathrm{~nm}$ band after $120 \mathrm{~min}$ irradiation of light suggests that concentration of residual $\mathrm{MB}$ is very low.

We studied the degradation of MB to verify the photocatalytic activity of aqueous suspensions of $\mathrm{Cu}_{2} \mathrm{O}$ NPs by irradiation with visible light. For this, we monitored the absorbance of $\mathrm{MB}$ solution at the absorption maximum wavelength $665 \mathrm{~nm}$. The \% degradation was calculated from the change in absorbance value during photodegradation with time of light irradiation. Figure 2 depicts the $\%$ degradation of $\mathrm{MB}$ before and after light irradiation against time of exposure. As can be seen from the Fig. 2, in the dark, the effect of photolysis on MB is not apparent. The concentration of $\mathrm{MB}$ solution slightly decreases due to the adsorption of $\mathrm{MB}$ on the surfaces of the catalyst. On the other hand, in presence of light, the \%decomposition of $\mathrm{MB}$ dye in presence of $\mathrm{Cu}_{2} \mathrm{O}$ NPs decreases non-linearly and reaches a value of $90 \%$ after 120 min of light exposure. The observed photodegradation efficiency of biosurfactant-capped $\mathrm{Cu}_{2} \mathrm{O}$ NPs on MB dye is due to presence of biosurfactant on its surface. The role of biosurfactant here is to promote charge carrier separation to enhance the photocatalytic efficiency. Cai et al. [10] have reported that the efficiency of $\mathrm{Cu}_{2} \mathrm{O}$ NPs has increased owing to introduction of rGO which act as charge carrier separator. In comparison to the work by Zou et al. [12], our sample has performed well and may be ascribed to small size of the $\mathrm{Cu}_{2} \mathrm{O}$ cluster as seen from TEM and FESEM images. In an article, Zho et al. [20] reported a similar decrease in the intensity of $665 \mathrm{~nm}$ band of $\mathrm{MB}$ by halloysite nanotube-

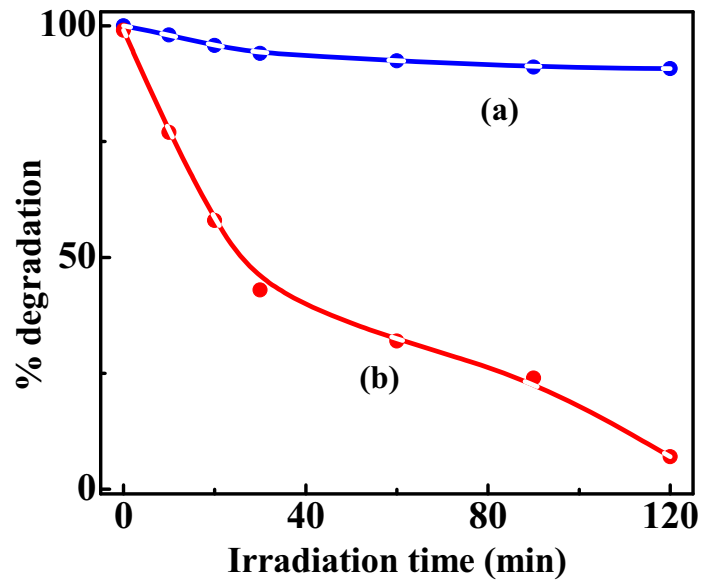

Fig. 2 Degradation of $20 \mathrm{mg} / \mathrm{L} \mathrm{MB}$ in presence of $\mathrm{Cu}_{2} \mathrm{O}$ NPs $a$ before and $b$ after visible light irradiation supported silver NPs. They have reported nearly $90 \%$ of MB degradation after $60 \mathrm{~min}$ irradiation. They ascribed superior efficiency to larger surface area of halloysite nanotubes.

\section{XRD pattern}

Figure 3 depicts the XRD pattern of $\mathrm{Cu}_{2} \mathrm{O}$ nanopowder (a) before and (b) after degrading $\mathrm{MB}$ dye. According to the JCPDS card no. 78-2076, both the patterns can be indexed as face-centered cubic structure [9-12]. Before adsorption of $\mathrm{MB}$ dye solution, the characteristic peaks (Fig. 3a) as observed at $2 \theta$ values of $29.3,36.8,42.3,61.4$, 73.5 , and 77.6 are assigned to the crystal planes of (110), (111), (200), (220), (311), and (222) of crystalline $\mathrm{Cu}_{2} \mathrm{O}$, respectively [9-12]. Form the most intense (111) peak, the crystallite size of $\mathrm{Cu}_{2} \mathrm{O}$ NPs before and after MB adsorption is found to be 8.8 and $9.3 \mathrm{~nm}$, respectively. The result implies that adsorption of MB dye on the surface of oxide particles hardly alters the crystallite size and the reclaimed $\mathrm{Cu}_{2} \mathrm{O}$ NPs retain their catalytic activity.

\section{FTIR spectra and DLS}

Figure 4 which depicts vibration spectra in the ranges $3200-800 \mathrm{~cm}^{-1}$ for MB (a) before and (b) after adsorption on the $\mathrm{Cu}_{2} \mathrm{O}$ NPs surface reveals photodegradation of the dye. As shown in Fig. 4a, the FTIR spectrum of MB shows three $\mathrm{C}-\mathrm{H}$ stretching bands $\left(2807,2866\right.$, and $\left.2924 \mathrm{~cm}^{-1}\right)$, one $\mathrm{C}-\mathrm{H}$ bending vibration $\left(920 \mathrm{~cm}^{-1}\right)$ and three $\mathrm{C}-\mathrm{N}$ stretching bands (1131, 1253 and $1352 \mathrm{~cm}^{-1}$ ) [21-23]. After 60 min of light irradiation, a significant decrease in the intensities of these bands occurs when the MB dye gets adsorbed via S-atom on the surface of oxide NPs. Yu et al. [23] reported that the intensity of vibration bands between

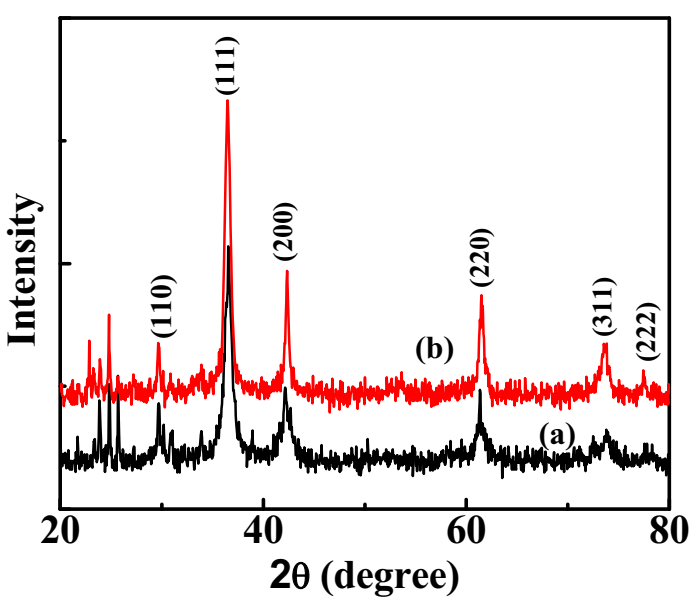

Fig. 3 XRD patterns of $\mathrm{Cu}_{2} \mathrm{O}$ NPs $a$ before and $b$ after MB adsorption 


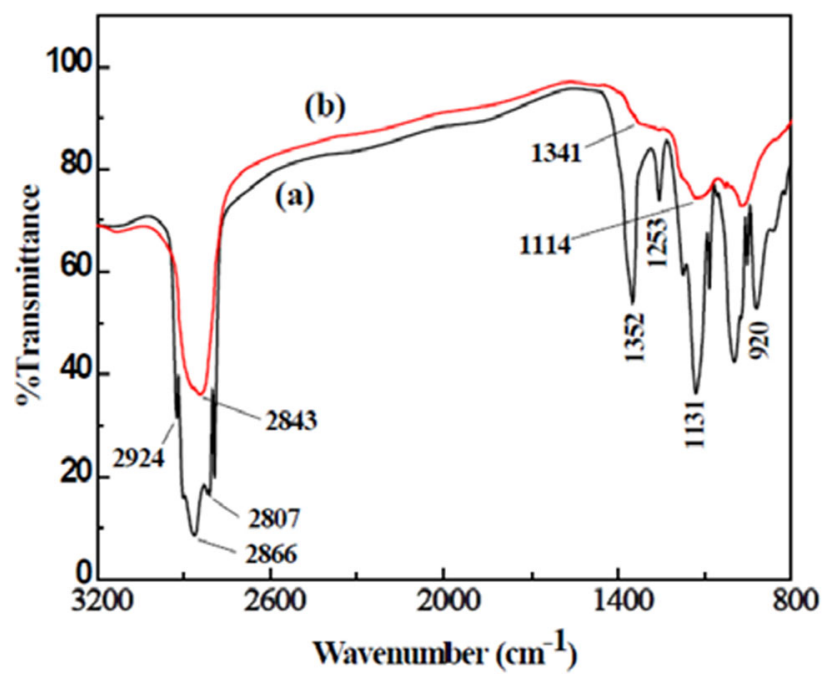

Fig. 4 FTIR spectra of MB $a$ before and $b$ after adsorption on $\mathrm{Cu}_{2} \mathrm{O}$ NPs surface

1700 and $1100 \mathrm{~cm}^{-1}$ of MB dye has decreased in presence of $\mathrm{TiO}_{2} \mathrm{NPs}_{\mathrm{s}}$ wen illuminated with visible light. In another report, Amini et al. [24] showed that upon lighting with visible light, the intensity of $\mathrm{C}-\mathrm{N}$ stretching band in $\mathrm{MB}$ dye has decreased drastically in presence of $\mathrm{MnO}_{x} / \mathrm{WO}_{3}$ catalyst and $\mathrm{H}_{2} \mathrm{O}_{2}$. A profound blue shift in these modes too indicates photodegradation of $\mathrm{MB}$ in presence of $\mathrm{Cu}_{2} \mathrm{O}$ NPs via surface adsorption process. A large blue shift of nearly $23 \mathrm{~cm}^{-1}$ that is from 2866 to $2843 \mathrm{~cm}^{-1}$ in the $\mathrm{C}-\mathrm{H}$ stretching band and nearly $3 \mathrm{~cm}^{-1}$ shift in $\mathrm{C}-\mathrm{N}$ stretching bands suggests interfacial interaction between $\mathrm{MB}$ and oxide NPs. Disappearance of $\mathrm{C}-\mathrm{H}$ bending vibration of heterocycle ring of $\mathrm{MB}$ in presence of oxide NPs also suggests that surface interaction arises between these two entities. In an experiment, Behera and Ram [25] have ascribed a small red shift of $5 \mathrm{~cm}^{-1}$ in the $\mathrm{C}=\mathrm{O}$ stretching vibration in presence of $\mathrm{Au}$ NPs to a weak interaction between poly(vinyl pyrrolidone) polymer and Au surface via the $\mathrm{O}$-atom of the pyrrolidone ring.

We also studied the size distributions of $\mathrm{Cu}_{2} \mathrm{O}$ NPs (a) before and (b) after $\mathrm{MB}$ adsorption which are shown in Fig. 5. As it is seen from the DLS profile, the average hydrodynamic diameter of $\mathrm{Cu}_{2} \mathrm{O}$ NPs has increased from 11.7 to $12.7 \mathrm{~nm}$. This clearly hints that the average size of $\mathrm{Cu}_{2} \mathrm{O}$ NPs has hardly increased when MB dye gets adsorbed on the oxide surface.

\section{Zeta potential and XPS study}

Figure 6 displays the distribution of zeta potential $(\xi)$ of $\mathrm{Cu}_{2} \mathrm{O}$ NPs (a) before and (b) after MB adsorption at $7.5 \mathrm{pH}$. As it is seen from the Fig. 6a, the zeta distribution profile of $\mathrm{Cu}_{2} \mathrm{O}$ NPs before MB addition gives an average $\xi$-value

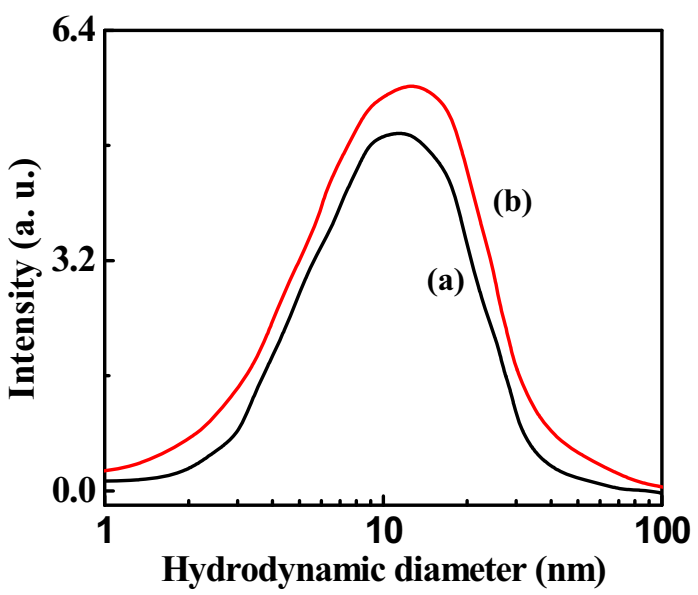

Fig. 5 Size distributions of $\mathrm{Cu}_{2} \mathrm{O}$ NPs $a$ before and $b$ after MB adsorption in an aqueous dispersion

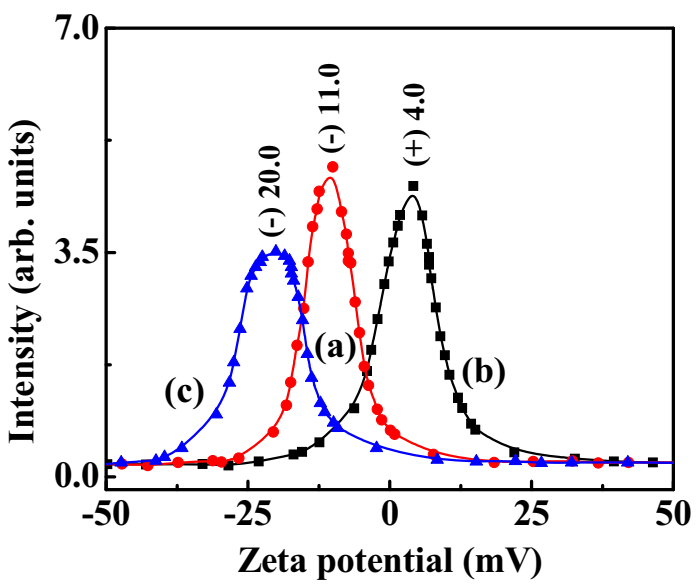

Fig. 6 Zeta potential distribution of $\mathrm{Cu}_{2} \mathrm{O}$ NPs $a$ before, $b$ immediately after MB addition and $c$ after 30 min of MB adsorption

(-) $11.0 \mathrm{mV}$. Negative zeta potential of $\mathrm{Cu}_{2} \mathrm{O}$ NPs represents accumulation of negative charges on the surface of oxide NPs. When MB dye is added to the aqueous suspension of $\mathrm{Cu}_{2} \mathrm{O}$ NPs and the $\xi$-value determined immediately, the sign has changed from negative to positive with an average $\xi$-value (+) $4.0 \mathrm{mV}$. The positive $\xi$-value could be ascribed to accumulation of positively charged S-atom of $\mathrm{MB}^{+}$dye (see Scheme 1) on the surface of oxide NPs. After $30 \mathrm{~min}$ of illumination, the same sample again acquires a negatively charged surface with an average $\xi$ value (-) $20.0 \mathrm{mV}$. This may be ascribed to accumulation of negatively charged electrons on the oxide surface when donation of non-bonding electrons of S-atom of $\mathrm{MBH}$ (see Scheme 2) occurs to the surface of $\mathrm{Cu}_{2} \mathrm{O}$ NPs [26]. Also it is observed from Table 1 that, when MB interacts with $\mathrm{Cu}_{2} \mathrm{O}$ NPs, the full width at half maximum (FWHM), i.e., width of zeta band has increased from 9.8 to $11.0 \mathrm{mV}$. This value has further increased to a value $13.7 \mathrm{mV}$ when it gets 


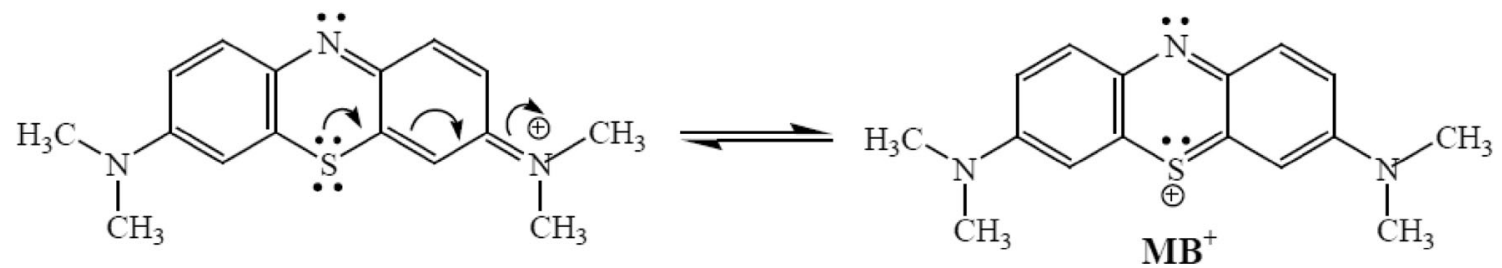

Scheme 1 Structure of methylene blue<smiles></smiles>

Scheme 2 Decolorization of methylene blue dye in presence of $\mathrm{Cu}_{2} \mathrm{O}$ NPs

Table 1 Zeta potentials and full width at half maximum (FWHM) values for $\mathrm{Cu}_{2} \mathrm{O}$ NPs before and after addition of $\mathrm{MB}$ dye

\begin{tabular}{llc}
\hline Samples & $\xi$-value $(\mathrm{mV})$ & FWHM $(\mathrm{mV})$ \\
\hline (a) $\mathrm{Cu}_{2} \mathrm{O}$ NPs before MB addition & $(-) 11.0$ & 9.8 \\
(b) $\mathrm{Cu}_{2} \mathrm{O}$ NPs immediately after MB addition & $(+) 4.0$ & 11.0 \\
(c) $\mathrm{Cu}_{2} \mathrm{O}$ NPs after 30 min of MB adsorption & $(-) 20.0$ & 13.7
\end{tabular}

adsorbed on the surface of oxide NPs. These results clearly hint that an interfacial interaction exists between MB and oxide NPs and extent of surface interaction increases with time. Yao and Wang [27] reported that the solution $\mathrm{pH}$ is an important parameter which controls the photodegradation efficiency of $\mathrm{TiO}_{2} \mathrm{NPs}$ on MB dye as it influences the sign of surface electrical charge of the oxide NPs. At pH 2, the average $\xi$-value of $\mathrm{TiO}_{2} \mathrm{NP}$ is reported to be (+) $19.04 \mathrm{mV}$ whereas at $\mathrm{pH} 9$, the average $\xi$-value of $\mathrm{TiO}_{2} \mathrm{NP}$ is (-) $25.49 \mathrm{mV}$.

XPS measurement was done to study the surface interaction between oxide NP and MB molecules and to finding the chemical state of copper $(\mathrm{Cu})$ atom in synthesized NPs. Figure 6a depicts the XPS spectrum recorded for $2 p$ photoelectrons of $\mathrm{Cu}(\mathrm{A})$ before and (B) after adsorption of MB molecules. In Fig. 6a, the XPS spectrum for $\mathrm{Cu}_{2} \mathrm{O}$ NPs before $\mathrm{MB}$ adsorption detects a doublet for $\mathrm{Cu} 2 p$ band, i.e., $\mathrm{Cu}^{2} p_{3 / 2}$ and $\mathrm{Cu}^{2} p_{1 / 2}$ at 932 and $952 \mathrm{eV}$, respectively [28]. In sample-B, i.e., after $\mathrm{MB}$ adsorption, the $\mathrm{Cu}^{2} p_{3 / 2}$ band appears at binding energy (BE) of $932.9 \mathrm{eV}$. The band at $932.9 \mathrm{eV}$ is assigned for $\mathrm{Cu}^{2} p_{3 / 2}$ peak of $\mathrm{Cu}^{0}$. It is suggested that when $\mathrm{Cu}_{2} \mathrm{O}$ NPs comes in contact with MB and irradiated with visible light, it oxidizes the dye and possibly itself gets reduced to $\mathrm{Cu}^{0}$ from $\mathrm{Cu}^{+}$state. The $\mathrm{O} 1 s$ peak of $\mathrm{Cu}_{2} \mathrm{O}$ NPs before and after MB adsorption is shown in Fig. $6 \mathrm{~b}$. The broad peak which centered at $530.7 \mathrm{eV}$ is for the metallic oxide $\left(\mathrm{O}^{2-}\right)$ [29]. Zhang et al. [11] have reported $\mathrm{O} 1 s$ peak of $\mathrm{Cu}_{2} \mathrm{O}$ NPs at $531.94 \mathrm{eV}$ owing to adsorbed $\mathrm{O}$-atom. It is seen from the spectra that the intensity of this broad peak has drastically decreased in presence of MB. It may be ascribed to change in the chemical state of metallic oxide $\left(\mathrm{O}^{2-}\right)$ when MB molecules get adsorbed on the surface of oxide NPs. Lu et al. [30] reported that a clean $\mathrm{Ti}$ sample does not give an $\mathrm{O} 1 s$ peak, but form a titanium oxide layer $\left(\mathrm{O}^{2-}\right)$ on the surface of $\mathrm{Ti}$ sample when exposed to excess oxygen, it results in a peak near $531.2 \mathrm{eV}$ (Figs. 7, 8).

\section{Photoluminescence study}

Figure 9 shows the emission spectra $(620-680 \mathrm{~nm})$ of $\mathrm{MB}-\mathrm{Cu}_{2} \mathrm{O}$ dispersions consisting of (a) 0 , (b) 1.0, (c) 2.0,

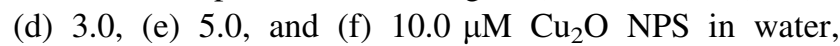
excited at $630 \mathrm{~nm}$. As it is seen from Fig. 9, addition of $1 \mu \mathrm{M} \mathrm{Cu}_{2} \mathrm{O}$ NPs caused only $18 \%$ quenching of emission intensity of $\mathrm{MB}$ molecules and it has reached about $78 \%$ after adding as large as $10 \mu \mathrm{M} \mathrm{Cu}_{2} \mathrm{O}$ NPs. Such a noticeable decay in the emission intensity is ascribed to existence of a surface interaction between oxide NP and MB molecules as non-bonding electron (n) transfer occurs from $\mathrm{S}$-atom of MBH molecules (see Scheme 2) to the surface of oxide NPs. Similar quenching in the emission intensity of various fluorophores was already reported in presence of an efficient light quencher like Au NP and ascribed to 

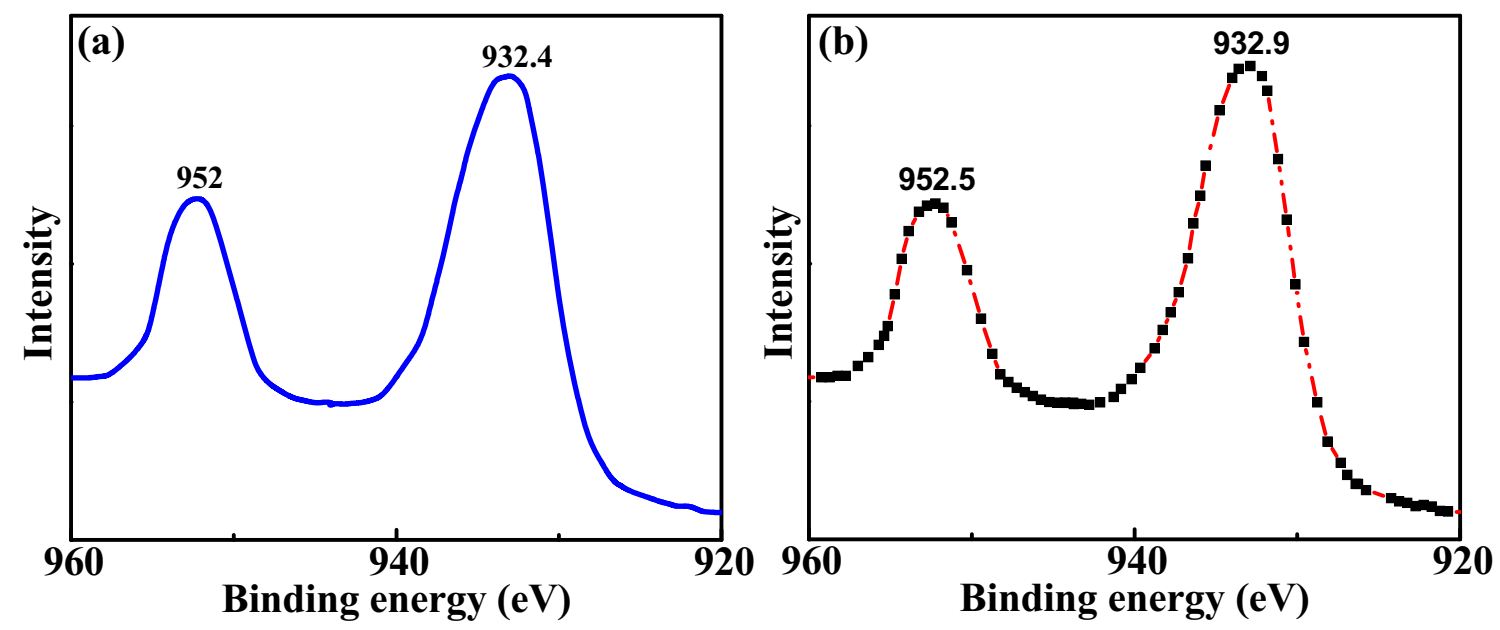

Fig. 7 XPS spectra (Cu2p bands) of $\mathrm{Cu}_{2} \mathrm{O}$ nanocrystals: a without and $\mathbf{b}$ with $\mathrm{MB}$ dye

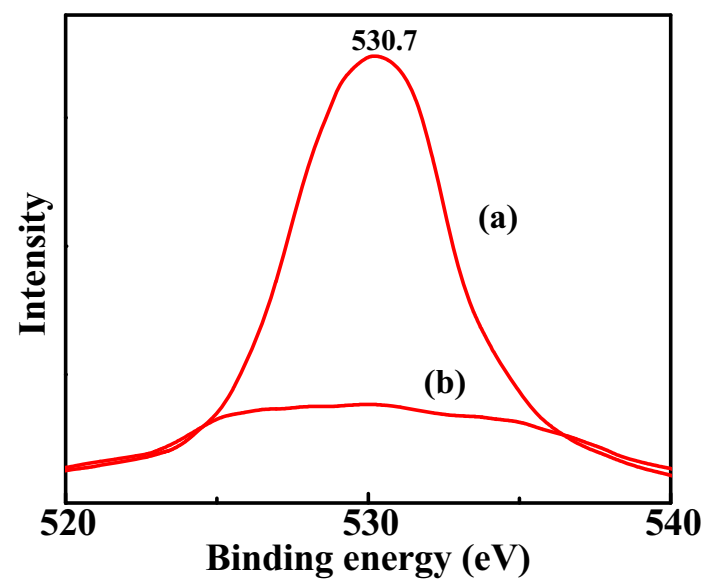

Fig. 8 XPS spectra (O1s band) of $\mathrm{Cu}_{2} \mathrm{O}$ nanocrystals: $a$ before and $b$ after MB dye adsorption

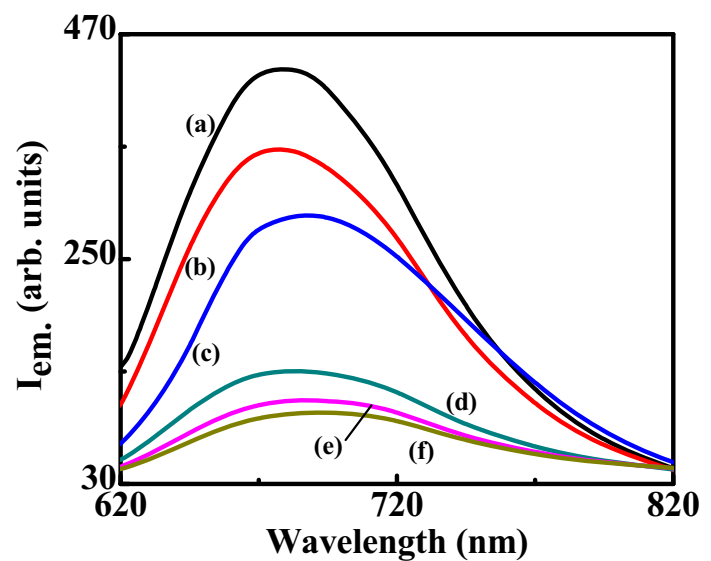

Fig. 9 Emission spectra of $\mathrm{MB}$ with different $\mathrm{Cu}_{2} \mathrm{O}$ NPs content in water; $a 0, b 1.0, c 2.0, d 3.0, e 5.0$, and $f 10.0 \mu \mathrm{M}$, excited at $630 \mathrm{~nm}$ charge transfer interaction between these two moieties [3134]. Zou et al. [12] have reported interfacial charge transfer process between different $\mathrm{Cu}_{2} \mathrm{O}$ crystal facets and $\mathrm{rGO}$ sheets. They ascribed the strong PL quenching in case of octahedral $\mathrm{Cu}_{2} \mathrm{O} / \mathrm{rGO}$ crystal to a strong interfacial interaction between $\mathrm{Cu}_{2} \mathrm{O}$ NPs and rGO sheets.

We also studied the variation of integrated emission intensity of $\mathrm{MB}$ molecules against $\mathrm{Cu}_{2} \mathrm{O}$ contents and it is found that emission intensity of $\mathrm{MB}$ molecules have quenched intensely by addition of $\mathrm{Cu}_{2} \mathrm{O}$ NPs (Fig. 10a).

Further we studied PL quenching of MB molecules in presence of an oxide quencher using the well-known SternVolmer equation $[25,34]$ which can be written as:

$F_{0} / F=1+K_{\mathrm{SV}}[Q]$

where ' $F_{0}$ ' and ' $F$ ' are the emission intensities of MB molecules in absence and presence of quencher (i.e., here it is $\mathrm{Cu}_{2} \mathrm{O} \mathrm{NPs}$ ); $[Q]$ is the concentration of quencher (i.e., $\mathrm{Cu}_{2} \mathrm{O}$ NP) and $K_{\mathrm{SV}}$ is quenching constant which tells about efficiency of a quencher. Figure $10 \mathrm{~b}$ demonstrates the dependence of $F_{0} / F$ on the concentration of $\mathrm{Cu}_{2} \mathrm{O}$ NP. A linear relationship between $F_{0} / F$ and $\mathrm{Cu}_{2} \mathrm{O}$ NPs content as observed from the plot reveals that only one type of quenching occurs in the system [33, 34]. We obtained a $K_{\mathrm{Sv}}$ value of $3.5 \times 10^{5} \mathrm{M}^{-1}$ which can be obtained from the slope of the linear line. A linear Stern-Volmer plot reveals dynamic quenching mechanism in this system [32, 34]. Further, such a large $K_{\mathrm{SV}}$ value suggests existence of strong surface interaction between $\mathrm{MB}$ molecules and $\mathrm{Cu}_{2} \mathrm{O}$ NP via S-atom of MBH molecule [32, 34, 35]. Tong et al. [35] have studied the interaction between MB dye and calf thymus deoxyribonucleic acid (ct-dRNA) by PL spectroscopic technique. In their study, they reported that 

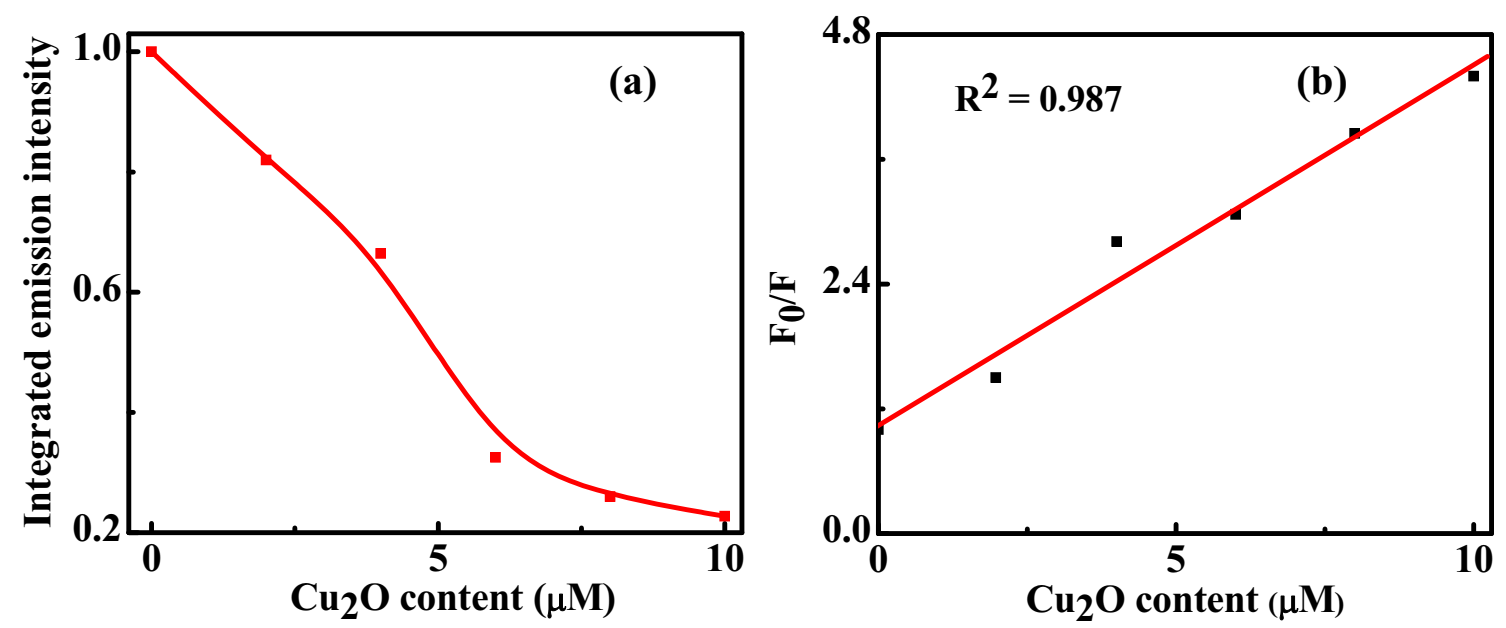

Fig. 10 a Variation of integrated emission intensity with $\mathrm{Cu}_{2} \mathrm{O}$ content and b Stern-Volmer plot of $F_{0} / F$ versus $\mathrm{Cu}_{2} \mathrm{O}$ content. The linear fit gives $F_{0} / F=1.04+0.35\left[\mathrm{Cu}_{2} \mathrm{O}\right]$

upon addition of $55.6 \mu \mathrm{M}$ ct-dRNA, the fluorescence intensity of $\mathrm{MB}$ can be quenched up to $80 \%$ with no shifts in the emission wavelength owing to intercalation binding between MB and the ct-dRNA.

\section{Microstructures}

Morphologies of oxide NPs were studied from the FESEM and TEM images. In Fig. 11a, the SEM image shows nanoclusters of various architectures whose average diameters lies in the range of 5-15 $\mathrm{nm}$. The TEM image in Fig. $11 \mathrm{~b}$ from the same sample also illustrates nanoclusters of various shapes and sizes. An average size of $10 \mathrm{~nm}$ is estimated from the TEM image. Data are well supported by the DLS data (discussed in "FTIR spectra and DLS" section). Uniform distributions of $\mathrm{Cu}_{2} \mathrm{O}$ NPs are observed from microscopic images. Zou et al. [12] have reported that relatively larger size particle lie in the range of 200-400 nm for $\mathrm{Cu}_{2} \mathrm{O}$ NPs of various shapes such as octahedral, dodecahedral and cubic crystals which were deposited on the surface of rGO.

\section{Conclusions}

We synthesized $\mathrm{Cu}_{2} \mathrm{O}$ NPs using a green chemistry route and studied the photodegradation of $\mathrm{MB}$ dye in the visible region in presence of $\mathrm{Cu}_{2} \mathrm{O}$ NPs in aqueous medium. Absorption spectra revealed that \%decomposition of $\mathrm{MB}$ dye decreases non-linearly with $\mathrm{Cu}_{2} \mathrm{O}$ contents and it reaches a value of $90 \%$ after light exposure for $120 \mathrm{~min}$. XRD result implies that adsorption of $\mathrm{MB}$ dye on the surface of oxide particles hardly alters the crystallite size. This implies that reclaimed $\mathrm{Cu}_{2} \mathrm{O}$ NPs will maintain their
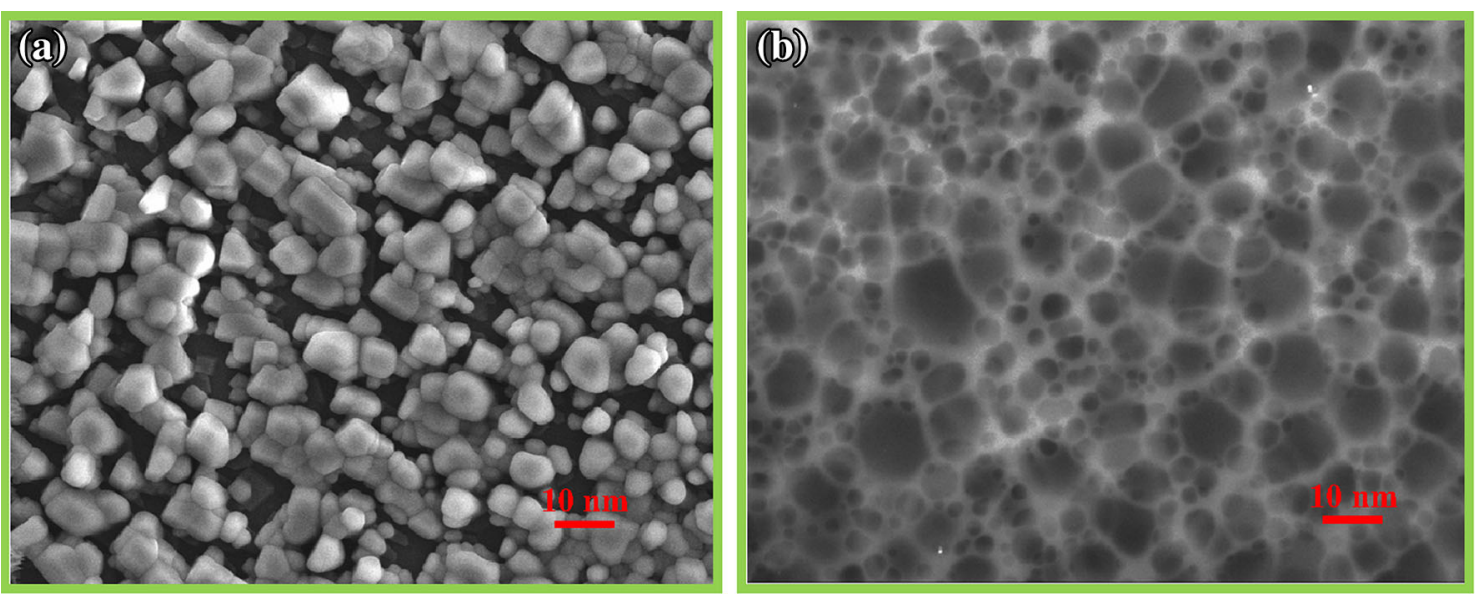

Fig. 11 a FESM image and b TEM image of surfactant-capped $\mathrm{Cu}_{2} \mathrm{O}$ NPs 
original catalytic activity. XPS, FTIR, and zeta potential measurements suggest that an interfacial interaction which exists between $\mathrm{MB}$ dye and $\mathrm{Cu}_{2} \mathrm{O}$ NPs is responsible for photodegradation of $\mathrm{MB}$ dye in presence of oxide NPs. Extensive quenching in the emission intensity of $\mathrm{MB}$ molecules in presence of $\mathrm{Cu}_{2} \mathrm{O}$ NPs is ascribed to existence of a charge transfer-type interaction between oxide NP and MB molecules as transference of non-bonding electron (n) occurs from $\mathrm{S}$-atom of $\mathrm{MBH}$ molecules to the surface of oxide NPs. A linear Stern-Volmer plot reveals existence of dynamic quenching mechanism in this system.

Acknowledgments Financial support of Silicon Institute of Technology is highly acknowledged.

Authors' contributions MB conceived the study, carried out all the experiments, and drafted the manuscript. GG helped MB in writing the manuscript. Both authors have read and approved the final manuscript.

\section{Compliance with ethical standards}

Conflict of interest The authors declare that they have no competing interests.

Open Access This article is distributed under the terms of the Creative Commons Attribution 4.0 International License (http://creati vecommons.org/licenses/by/4.0/), which permits unrestricted use, distribution, and reproduction in any medium, provided you give appropriate credit to the original author(s) and the source, provide a link to the Creative Commons license, and indicate if changes were made.

\section{References}

1. Kar A, Smith YR, Subramaniam V (2009) Improved photocatalytic degradation of textile dye using titanium dioxide nanotubes formed over titanium wires. Environ Sci Technol 43:3260

2. Ma W, Li J, Tao X, He J, Xu Y, Yu JC, Zhao J (2003) efficient degradation of organic pollutants by using dioxygen activated by resin-exchanged iron(II) bipyridine under visible irradiation. Angew Chem Int Ed 42:1029

3. Pal J, Ganguly M, Mondal C, Roy A, Negishi Y, Pal T (2013) Crystal-plane-dependent etching of cuprous oxide nanoparticles of varied shapes and their application in visible light photocatalysis. J Phys Chem C 117:24640

4. Pourahmad A (2012) $\mathrm{Ag}_{2} \mathrm{~S}$ nanoparticle encapsulated in mesoporous material nanoparticles and its application for photocatalytic degradation of dye in aqueous solution. Supperlattices Microstruct 52:276

5. Turhan K, Ozturkcan SA (2012) Decolorization and degradation of reactive dye in aqueous solution by ozonation in a semi-batch bubble column reactor. Water Air Soil Pollut 224:1353

6. Salleh MAM, Mahmoud DK, Karim WAWA, Idris A (2011) Cationic and anionic dye adsorption by agricultural solid wastes: A comprehensive review. Desalination 280:1

7. Nassar MM, Magdy YH (1997) Removal of different basic dyes from aqueous solutions by adsorption on palm-fruit bunch particles. Chem Eng J 66:223

8. Vasanthkumar K, Ramamurthi V, Sivanesan SJ (2005) Modeling the mechanism involved during the sorption of methylene blue onto fly ash. Colloid Interface Sci 284:14
9. Sun L, Wang G, Hao R, Han D, Cao S (2015) Solvothermal fabrication and enhanced visible light photocatalytic activity of $\mathrm{Cu}_{2} \mathrm{O}$-reduced graphene oxide composite microspheres for photodegradation of rhodamine B. Appl Surf Sci 358:91

10. Cai J, Liu W, Li Z (2015) One-pot self-assembly of $\mathrm{Cu}_{2} \mathrm{O} / \mathrm{RGO}$ composite aerogel for aqueous photocatalysis. Appl Surf Sci 358:146

11. Zhang D, Hu B, Guan D, Luo Z (2016) Essential roles of defects in pure graphene/ $\mathrm{Cu}_{2} \mathrm{O}$ photocatalyst. Catal Commun 76:7

12. Zou W, Zhang L, Liu L, Wang X, Sun J, Wu S, Deng Y, Tang C, Gao F, Dong L (2016) Engineering the $\mathrm{Cu}_{2} \mathrm{O}$-reduced graphene oxide interface to enhance photocatalytic degradation of organic pollutants under visible light. Appl Catal B Environ 181:495

13. Srinivasan M, White T (2007) Degradation of methylene blue by three-dimensionally ordered macroporous titania. Environ Sci Technol 41:4405

14. Zheng Z, Huang B, Wang Z, Guo M, Qin X, Zhang X, Wang P, Dai Y (2009) Crystal faces of $\mathrm{Cu}_{2} \mathrm{O}$ and their stabilities in photocatalytic reactions. J Phys Chem C 113:14448

15. Zhang Y, Deneg B, Zhang T, Gao D, Xu AW (2010) Shape effects of $\mathrm{Cu}_{2} \mathrm{O}$ polyhedral microcrystals on photocatalytic activity. J Phys Chem C 114:5073

16. Abboud Y, Saffaz T, Chagraoui A, Bouari LL, Brouzi K, Tanane O, Ihssane B (2014) Biosynthesis, characterization and antimicrobial activity of copper oxide nanoparticles (CONPs) produced using brown alga extract (Bifurcaria bifurcata). Appl Nanosci 4:571

17. Zhu Q, Zhang Y, Wang J, Zhou F, Chu P (2011) Microwave synthesis of cuprous oxide micro-/nanocrystals with different morphologies and photocatalytic activities. J Mater Sci Technol 27:289

18. Behera M, Giri G (2014) Green synthesis and characterization of cuprous oxide nanoparticles in presence of a bio-surfactant. Mater Sci Pol 32:702

19. Donnan FG, Thomas JS (1911) The solubility of cuprous oxide in aqueous ammonia solutions, and the composition of the cuprousammonia complex. J Chem Soc Trans 99:1788

20. Zou M, Du M, Zhu H, Xu CS, Fu YQ (2012) Green synthesis of halloysite nanotubes supported $\mathrm{Ag}$ nanoparticles for photocatalytic decomposition of methylene blue. J Phys D Appl Phys 45:325302

21. Ovchinnikov OV, Chernykh SV, Smirnov MS, Alpatova DV, Vorob'eva RP, Latyshev AN, Evlev AB, Utekhin AN, Lukin AN (2007) Analysis of interaction between the organic dye methylene blue and the surface of $\mathrm{AgCl}(\mathrm{I})$ microcrystals. J Appl Spectrosc 74:809

22. Colthup NB, Daly LH, Wiberley SE (eds) (1990) Introduction to infrared and raman spectroscopy. Academic Press, Boston

23. Yu Z, Chuang SSC (2007) Probing methylene blue photocatalytic degradation by adsorbed ethanol with in situ IR. J Phys Chem C 111:13813

24. Amini M, Pourbadiei B, Purnima T, Ruberub A, Woob LK (2014) Catalytic activity of $\mathrm{MnO}_{\mathrm{x}} / \mathrm{WO}_{3}$ nanoparticles: synthesis, structure characterization and oxidative degradation of methylene blue. New J Chem 38:1250

25. Behera M, Ram S (2013) Spectroscopy-based study on the interaction between gold nanoparticle and poly (vinylpyrrolidone) molecules in a non-hydrocolloid. Int Nano Lett 3:17

26. Anderson L, Wittkopp SM, Painter CJ, Lligel JJ, Schreiner R, Bell JA, Shakhasiri BZ (2012) What is happening when the blue bottle bleaches: An investigation of the methylene blue-catalyzed air oxidation of glucose. J Chem Edu 89:1425

27. Yao J, Wang, C (2010) Decolorization of methylene blue with sol via UV irradiation photocatalytic degradation. Int J Photoenergy. Article ID 643182, 6 
28. Yin M, Wu C, Lou Y, Burda C, Koberstein J, Zhu Y, O'briens S (2005) Copper oxide nanocrystals. J Am Chem Soc 127:9506

29. Heng B, Xiao OT, Tao W, Hu X, Chen X, Wang B, Sun D, Tang Y (2012) Zn doping-induced shape evolution of microcrystals: the case of cuprous oxide. Cryst Growth Des 12:3998

30. Lu G, Stevan LB, Jeffery S (2000) Oxidation of a polycrystalline titanium surface by oxygen and water. Surf Sci 458:80

31. Alexandridis P (2011) Gold nanoparticle synthesis, morphology control, and stabilization facilitated by functional polymers. Chem Eng Technol 34:15

32. Lakowicz JR (1999) Principles of fluorescence spectroscopy. Plenum Press, New York
33. Pramanik S, Banerjee P, Sarkar A, Bhattacharya SC (2008) Sizedependent interaction of gold nanoparticles with transport protein: a spectroscopic study. J Lumin 128:1969

34. Behera M, Ram S (2013) Intense quenching of fluorescence intensity of poly (vinyl pyrrolidone) molecules in presence of gold nanoparticles. Appl Nanosci 3:543

35. Tong C, Hu Z, Wu J (2010) Interaction between methylene blue and calfthymus deoxyribonucleic acid by spectroscopic technologies. J Fluoresc 20:261 